\title{
Quantifying the effect of glidant on the compaction and tableting properties of paracetamol granules
}

\author{
Yonni Eshovo APEJI ${ }^{*}$ * iD, Adeniji Kehinde OLOWOSULU1 (i) \\ 1 Department of Pharmaceutics and Industrial Pharmacy, Faculty of Pharmaceutical Sciences, Ahmadu Bello \\ University, Zaria, Nigeria. \\ * Corresponding Author. E-mail: yehonathanapeji@gmail.com (Y.E.A.); Tel. +234-805-262 2947.
}

Received: 24 September 2019 / Revised: 04 December 2019/ Accepted: 09 December 2019

\begin{abstract}
Glidants play a vital role in tablet formulation. This study aimed to examine the impact of glidants on the compaction and tableting properties of paracetamol granules prepared by wet granulation. Three formulations of paracetamol granules were prepared to consist of either talc, colloidal silicon dioxide (CSD) or a combination of both in equal proportion (1:1) as glidants added extragranularly. The granules were characterised by measuring the particle size, angle of repose, bulk and tapped densities, true densities, and moisture content. Compaction studies on the granules were carried out using the Heckel, Kawakita, Walker, and compressibility-tabletability-compactibility (CTC) models. Tablets were prepared from the granules for each formulation and evaluated according to USP requirements. The results of the granule analysis revealed that granule properties were similar across the formulations irrespective of the type of glidant used. Compaction studies revealed that talc granules exhibited a greater degree of plasticity and compressibility compared to the other formulations. However, CSD granules and granules containing the two glidants in equal proportion were found to have better compactibility and tabletability, resulting in tablets with relatively better properties. This study has underscored the impact of glidants on the compaction and tableting properties of paracetamol granules.
\end{abstract}

KEYWORDS: Colloidal silicon dioxide; talc; glidant; compaction properties; tableting properties.

\section{INTRODUCTION}

Glidants constitute a category of tableting excipients added externally to a formulation to enhance the flow of granulates or powders in tablet dosage form development [1,2]. They act in conjunction with lubricants to ensure the uniform filling of the die cavity during tableting leading to the formation of tablets uniform in weight and content and devoid of defects associated with sticking [3-6]. By their mode of incorporation, glidants exert their action on the surface of the solid particles, potentially affecting not only the processing performance but also the finished product quality attributes. They act by coating the surface of solid particles, thereby modifying the surface properties of powders and granules. Because glidants exert their effect on the surface, they are more likely to influence tablet formation characteristics owing to their presence at bonding surfaces. Interparticulate bonding is a common feature in tablet formation; hence, the morphology of the bonding surfaces plays a crucial role in determining the tabletability of the formulation [7]. The tabletability of a material is a function of its compressibility and compactibility. Compressibility refers to the ability of a material to undergo volume reduction when pressure is applied and has been associated with an increase in bonding area while compactibility refers to the ability of a material to form compacts of sufficient mechanical strength under the effect of densification. These two properties involve bonding surfaces which can be modified in the presence of glidants like talc and colloidal silicon dioxide. In a study carried out by Müller et al. [8], the use of precipitated silica as a flow regulator increased the roughness of the solid surface, contributing to tablet formation. Another study carried out by Nurnberg [9] showed improvement in the compactibility of powders upon addition of colloidal silicon dioxide (CSD), a glidant. Co-processing chitin with CSD was also found to improve the compaction characteristics of chitin [10]. These outcomes reveal the role played by glidants in modulating the compaction and tableting properties of powders or granules. The focus of studies carried out on glidants had been to evaluate its performance on the flowability of powders $[2,11,12]$. However, to the best of our knowledge, not much attention has been given to quantifying the impact

How to cite this article: Apeji YE, Olowosulu AK. Quantifying the effect of glidant on the compaction and tableting properties of paracetamol granules. J Res Pharm. 2020; 24(1): 44-55. 
of glidants on the compaction and tableting properties of a powder or granules. The aim of the present study, therefore, was to investigate the effect of glidants on the compaction and tableting properties of paracetamol granules prepared by wet granulation. Paracetamol granules were formulated employing CSD and Talc as glidants. CSD is a white, fluffy, odourless and tasteless powder that is either hydrophilic or hydrophobic [2]. It has been used widely as a glidant and antistatic agent in tablet and capsule formulations to promote the flow of granulation and prevent caking, clumping or formation of lumps during processing [2]. It is light, having a low bulk density and composed of semi-spherical nanoparticles occurring as aggregates. According to Majerova et al. [13], CSD is one of the most efficient glidants and improves the flow of cohesive powders and granulates when incorporated in a concentration between $0.2-1 \% \mathrm{w} / \mathrm{w}$. However, under dynamic flow test conditions, maximum flowability of granules was obtained at concentrations exceeding $1 \%$ for CSD [12]. As a compressibility enhancing agent, CSD is incorporated in concentrations ranging from $0.1 \%-20 \% \mathrm{w} / \mathrm{w}$ [14]. Talc is hydrous magnesium silicate, sometimes containing a small amount of aluminium silicate and possesses high bulk and tapped densities when compared to CSD [15]. It is usually added in the range of 1-10 $\%$ when evaluated as a glidant [5]. The levels of CSD and talc used in the formulation for this study were adopted from a previous study carried out in our laboratory where the levels of CSD and talc were optimised using the design of experiment [16]. The effects of these glidants on compaction and tableting properties were evaluated individually and then combined in equal proportion.

\section{RESULTS}

\subsection{Physical properties of granules}

Table 1 summarises the physical properties of formulations I - III granules. The mean particle size of granules for all the formulations ranged from 459.53 - $478.24 \mu \mathrm{m}$ with formulation III having the largest mean granule size. Formulation II granules containing CSD as glidant returned a slightly larger mean granule size compared to formulation I granules formulated with talc as a glidant. The mean granule size obtained for the granules did not differ widely from each other irrespective of the type of glidant used either singly or in combination.

Table 1. Physical properties of granules.

\begin{tabular}{llll}
\hline & \multicolumn{3}{c}{ Formulations } \\
\cline { 2 - 4 } Parameters & I & II & III \\
\hline Mean granule size $(\mu \mathrm{m})$ & 459.53 & 468.59 & 478.24 \\
Angle of repose $\left(^{\circ}\right)$ & $31.9(1.42)^{*}$ & $34.4(0.21)$ & $31.7(0.92)$ \\
Flow rate $(\mathrm{g} / \mathrm{s})$ & $3.33(0.02)$ & $3.56(0.06)$ & $3.49(0.04)$ \\
Bulk density $(\mathrm{g} / \mathrm{mL})$ & $0.38(0.01)$ & $0.40(0.0)$ & $0.37(0)$ \\
Tapped density $(\mathrm{g} / \mathrm{mL})$ & $0.4(0.0)$ & $0.44(0.01)$ & $0.44(0)$ \\
Hausner's ratio & $1.04(0.03)$ & $1.10(0.02)$ & $1.19(0.02)$ \\
Carr's index $(\%)$ & $3.81(2.62)$ & $9(1.41)$ & $15.88(1.11)$ \\
True density $(\mathrm{g} / \mathrm{mL})$ & $1.28(0.01)$ & $1.28(0.03)$ & $1.32(0.09)$ \\
Moisture content $(\%)$ & 1 & 0 & 4 \\
\hline
\end{tabular}

*Values in parentheses are standard deviation values.

Formulation I granules - Talc as a glidant.

Formulation II granules - Colloidal silicon dioxide as a glidant.

Formulation III granules - Combination of talc and colloidal silicon dioxide as a glidant in equal proportion.

Granules' flow properties were assessed by measuring the angle of repose and flow rate. The values obtained for the angle of repose ranged from $31.7-34.4^{\circ}$, suggesting that all the formulations of granules possessed excellent flow properties. The flow rate index also confirmed the rapid flow of the granules.

Bulk and tapped density values did not differ significantly across the formulations as the values ranged from $0.37-0.4 \mathrm{~g} / \mathrm{mL}$. Flowability indices of Carr's index and Hausner's ratio not exceeding $20 \%$ and 1.2 respectively confirmed the ease of flowability of the three formulations of granules. True density, an index for packability did not differ significantly across the formulations with values ranging from $1.28-1.32 \mathrm{~g} / \mathrm{mL}$. The moisture content recorded for all formulations did not exceed $4 \%$. Overall, the properties of the granules did not differ significantly across the formulations irrespective of the type of glidant used. 


\subsection{Compaction properties}

Figure 1 is an illustration of the compaction plots for formulations I - III granules comprising Heckel, Kawakita, and Walker plots.
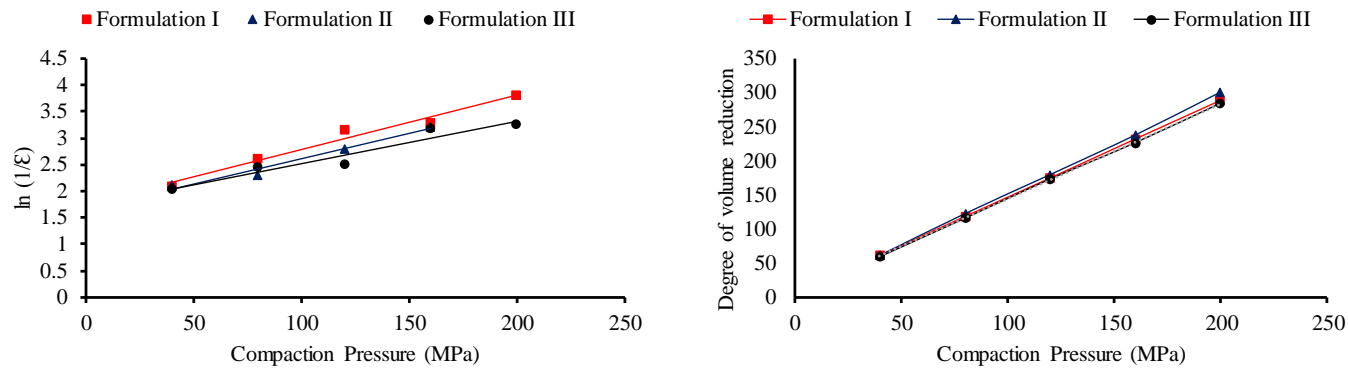

A

B

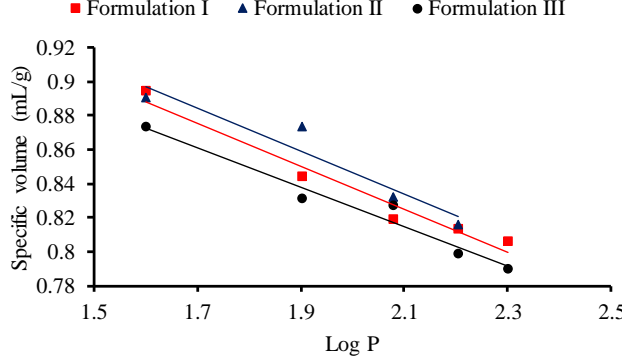

C

Figure 1. Compaction plots for formulations I - III granules, (A) Heckel Plot, (B) Kawakita Plot, and (C) Walker Plot.

The Heckel Plot (Fig. 1A) relates the natural logarithm of the inverse porosity of the compacts to the applied compaction pressure. There was a decrease in porosity with an increase in compaction pressure across all the formulations. The mean yield pressure $\left(P_{Y}\right)$ that estimates the degree of plasticity of the granules was extrapolated from the linear portion of the plot. $P_{Y}$ values ranged from $97.09-125 \mathrm{MPa}$ with formulation I granules having the least value implying a faster onset of plastic deformation. Other Heckel parameters $\left(D_{A}\right.$, $D_{B}, \mathcal{E} D_{0}$ ) derived from the plot are presented in Table 2.

Table 2. Heckel, Kawakita and Walker parameters for formulation I, II \& III granules.

\begin{tabular}{|c|c|c|c|c|c|c|c|c|}
\hline \multirow[b]{2}{*}{ Batch } & \multicolumn{3}{|c|}{ Heckel } & \multirow[b]{2}{*}{$\mathrm{D}_{\mathrm{B}}$} & \multicolumn{3}{|c|}{ Kawakita } & \multirow{2}{*}{$\begin{array}{l}\text { Walker } \\
\text { W' }^{\prime}(\%) \\
\end{array}$} \\
\hline & $P_{Y}(\mathrm{MPa})$ & $\mathrm{D}_{\mathrm{A}}$ & $\mathrm{D}_{0}$ & & $a$ & $b$ & $\mathbf{P}_{\mathrm{K}}$ & \\
\hline $\mathrm{I}$ & 97.09 & 0.828 & 0.314 & 0.516 & 0.703 & 0.383 & 2.61 & 12.73 \\
\hline II & 104.17 & 0.807 & 0.344 & 0.463 & 0.677 & 0.440 & 2.27 & 12.65 \\
\hline III & 125 & 0.822 & 0.333 & 0.480 & 0.714 & 0.408 & 2.45 & 11.6 \\
\hline
\end{tabular}

Formulation I granules - Talc as a glidant.

Formulation II granules - Colloidal silicon dioxide as a glidant.

Formulation III granules - Combination of talc and colloidal silicon dioxide as a glidant in equal proportion.

The $D_{A}$ parameter reflects the extent of consolidation occurring in the powder bed at the early stages of compression. There was no significant variation across the formulations as values ranged from $0.807-0.828$. Also, densification attributed to particle motion and filling of the die at low pressures $\left(D_{0}\right)$ did not differ significantly between formulations. The degree of densification occurring as a result of particle fragmentation was slightly higher with formulation I granules in comparison to the other two formulations (II \& III) that had almost similar values.

Kawakita plot (Fig. 1B) relates the degree of volume reduction with compaction pressure. The plot shows that all the batches demonstrated the ability to contract in volume under the effect of applied pressure. The ' $a$ ' parameter under Kawakita analysis describes the minimum porosity of the material before compression. Higher values reveal the extent of packing that occurred before compression. Values ranged 
from 0.68-0.71 with formulation II having the highest value. The ' $b$ ' parameter reflects the plasticity of the material and the reciprocal of $b\left(P_{K}\right)$ is a measure of the pressure that is required to decrease the volume of the powder bed by $50 \%$. The values obtained for $P_{K}$ did not differ significantly, implying that the degree of plasticity was almost similar for all formulations.

The Walker's $W^{\prime}$ coefficient of compressibility indicates that formulations I \& II granules are slightly more compressible than formulation III owing to the higher value obtained as compressibility coefficient $\left(W^{\prime}\right)$ for formulations I \& II granules (Table 2).

The ability of granules to be transformed into tablets when compressed was also evaluated using the compressibility-tabletability-compactibility (CTC) plot. Figure 2 represents CTC plot for the three formulations of granules.

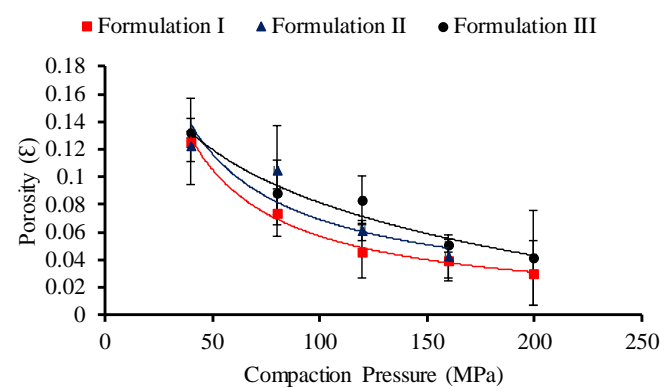

A

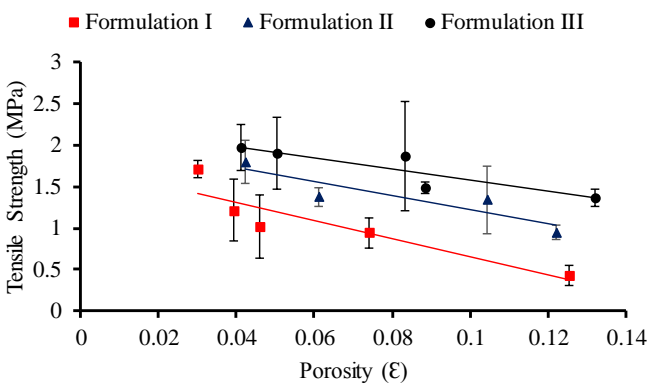

B

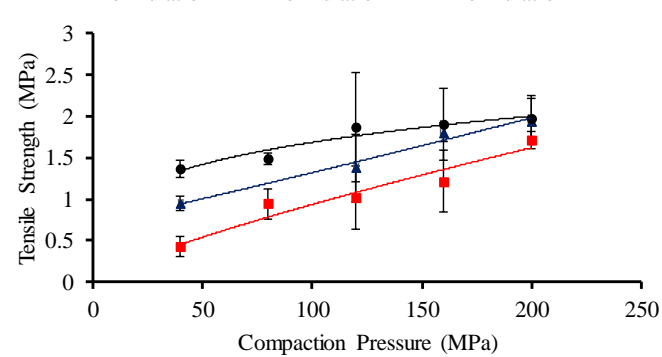

C

Figure 2. CTC Plots for formulations I - III granules, (A) Compressibility Plot, (B) Compactibility Plot, and (C) Tabletability Plot.

The compressibility plot (Fig. 2A) portrays the relationship between applied pressure and the porosity of the compacts. The porosity of compacts decreased with increasing pressure for all the formulations. Formulation I granules exhibited the least reduction in porosity compared to other batches, implying a higher degree of densification occurring with the formulation I granules. Fig. 2B represents the compactibility plot showing the effect of densification as a result of decreasing porosity on the tensile strength of compacts. The tensile strength of compacts increased across all the formulations of granules with decreasing levels of porosity. At the same level of porosity, the compactibility of formulation III granules ranked higher than formulations I and II granules, respectively (III > II > I). It implies, therefore, that higher tensile strength values were obtained with formulation III granules at the same level of porosity when compared to formulations I and II granules, respectively.

The tabletability plot (Fig. 2C) graphically illustrates the relationship between the tensile strength of tablets and applied pressure. Tensile strength increased as compaction pressure increased across all the formulations. Formulation III granules produced tablets with the highest tensile strength across all the pressures applied while formulation I granules produced tablets with the least tensile strength.

\subsection{Tableting properties}

The tablet properties obtained for the three formulations of granules prepared are summarised in Table 3. 
Table 3. Tablet properties of formulations I - III granules.

\begin{tabular}{lccccccc}
\hline Batches & $\begin{array}{c}\text { Weight } \\
\mathbf{( m g )}\end{array}$ & $\begin{array}{c}\text { Thickness } \\
\mathbf{( m m )}\end{array}$ & $\begin{array}{c}\text { Tablet } \\
\text { Porosity }\end{array}$ & $\begin{array}{c}\text { Crushing } \\
\text { strength } \\
\mathbf{( N )}\end{array}$ & $\begin{array}{c}\text { Tensile } \\
\text { strength } \\
(\mathbf{M P a})\end{array}$ & $\begin{array}{c}\text { Disintegration } \\
\text { time }(\mathbf{m i n})\end{array}$ & $\begin{array}{c}\text { Friability } \\
\mathbf{( \% )}\end{array}$ \\
\hline I & $650(7.7)$ & $5.5(0.06)$ & $0.14(0.01)$ & $112(11)$ & $1.09(0.10)$ & $1.18(0.59)$ & 0.82 \\
II & $643(5.8)$ & $5.5(0.04)$ & $0.16(0.01)$ & $136(5.5)$ & $1.30(0.06)$ & $0.84(0.37)$ & 0.76 \\
III & $653(7.7)$ & $5.5(0.04)$ & $0.18(0.02)$ & $140(0)$ & $1.35(0.02)$ & $>15$ & 0.61 \\
\hline
\end{tabular}

*Values in parentheses are standard deviation values.

Formulation I granules - Talc as glidant.

Formulation II granules - Colloidal silicon dioxide as glidant

Formulation III granules - Combination of talc and colloidal silicon dioxide as glidant in equal proportion.

Tablet thickness was constant for all the formulations and was not affected by the mean weight of the tablet. The crushing and tensile strengths ranged from $112-140 \mathrm{~N}$ and $1.09-1.35 \mathrm{MPa}$, respectively. Friability values were consistent with the values obtained for crushing and tensile strength. Disintegration time was rapid for formulations I \& II tablets but exceeded the limit of 15 mins for formulation III tablets.

The calibration curve of paracetamol is given in Figure 3. The straight line equation resolved from the plot was found to be, $y=0.1925 x+0.1349$ with a degree of linearity, $r^{2}=0.9913$.

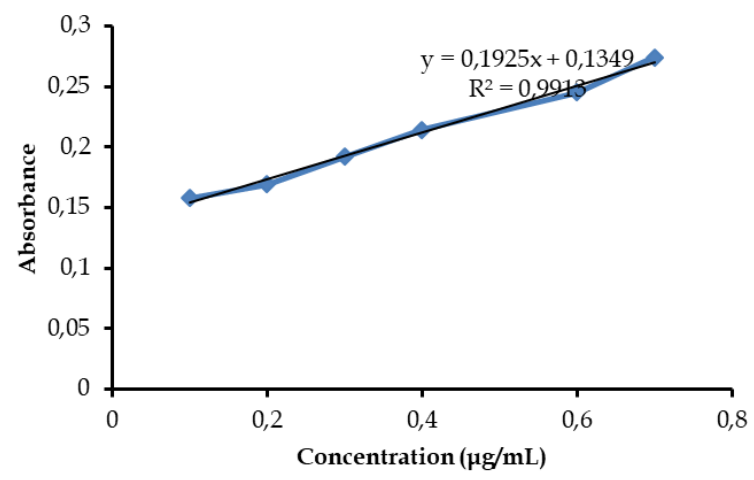

Figure 3. Calibration curve for paracetamol.

The amount of drug released after 60 mins of dissolution studies did not exceed $60 \%$ with formulation II tablets giving the highest drug release. The release profile of formulation III tablets did not exceed $40 \%$ (Fig. 4), which was consistent with the disintegration time.

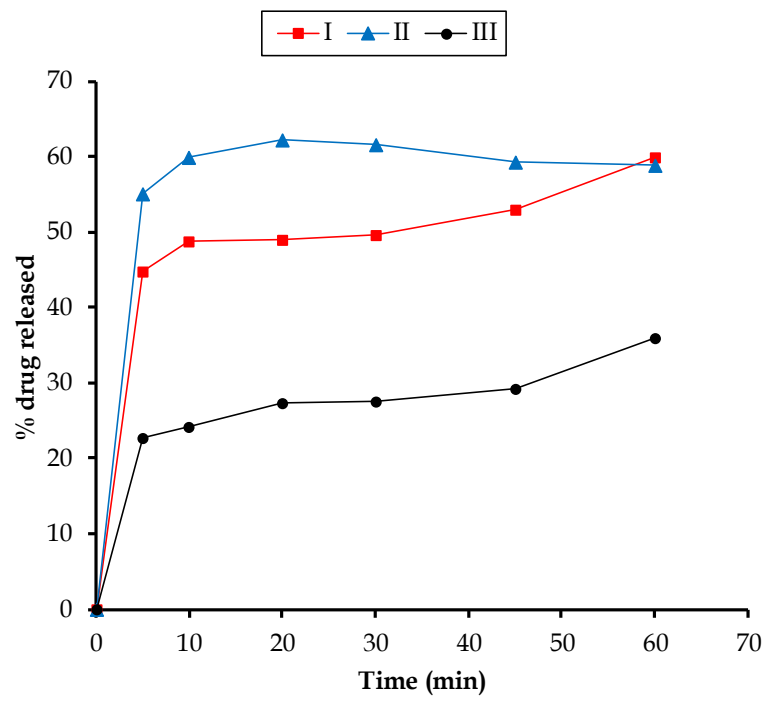

Figure 4. Drug release profile for formulations I - III tablets. 


\section{DISCUSSION}

\subsection{Granule properties}

The formulation of tablets either by wet or dry granulation requires the addition of extragranular excipients like glidants to the granules before tablet compression. In this study, two different glidants, talc, and CSD were used either singly or in combination to assess the impact of glidants on the granular, compaction, and tableting properties. The results of the granule analysis show that the granule parameters examined after the addition of the glidants did not differ significantly across the formulations. The granule properties were found to be similar, implying that varying the glidant used did not produce a wide variation in granule properties. All the formulations of granules had similar properties, possibly because the composition of the granules and process of granulation were kept constant for all the formulations. The formulation variable across the formulations was related to the type of glidant used, but this was not enough to cause a wide variation in the properties of granules examined. Hence, the properties of granules may broadly be defined by the composition of the granules before the addition of extragranular excipients.

\subsection{Compaction properties}

The ability of granules to be transformed into tablets of suitable mechanical strength under the effect of applied pressure is influenced by the compaction behaviour of the granules [17,18]. Granules, when compressed, undergo deformation and bonding to form tablets with suitable mechanical strength. The study shows that the type of glidant used in the formulation influenced the compaction behaviour of the granules. The Heckel yield pressure $(P y)$, which describes the onset of plastic deformation during compaction differed significantly across the three batches of granules. Formulation I granules containing talc as glidant had the lowest $P y$ indicating a faster onset of plastic deformation relative to the other formulations. This implies, therefore, that the incorporation of talc as a glidant promotes rapid densification of the granules during compaction compared to CSD and when used in combination with CSD in equal proportion as a glidant. Changes in the surface properties of the granules may have been responsible for the effect of talc observed on densification. Due to its adsorptive capacity, talc provides a large surface area at interparticle surfaces, thereby influencing plastic deformation [15]. However, densification occurring as a result of particle fragmentation $\left(D_{B}\right)$ was slightly higher for talc granules, producing tablets of lower tensile strength compared to those of CSD granules. Particle fragmenting materials are more likely to produce tablets of lower tensile strength compared to materials that consolidate by plastic deformation [19]. Hence, talc granules consolidated by plastic deformation with some degree of particle fragmentation occurring during compaction. Relative to talc granules, the yield pressure of CSD granules was slightly higher with a lower degree of particle fragmentation $\left(D_{B}\right)$ resulting in tablets of higher tensile strength. This agrees with the findings of other researchers where the inclusion of CSD as glidant improved the compactibility of the formulation giving rise to stronger tablets $[20,21]$. Combining the two glidants in equal proportion, however, did not improve the degree of plasticity of the formulation (Formulation III) evidenced by the relatively high yield pressure obtained (Table 3). The combined effect of the two glidants increased resistance to plastic deformation possibly attributed to the thickness of the glidant layer formed on the surface of the granules which may have reduced the ability of the granules to adhere during consolidation thereby increasing the pressure required to initiate plastic deformation. This explanation is based on the bonding area-bonding strength theory developed by Sun [22], which highlights the role of particle adhesion and plasticity in tablet formation. The outcome of the Kawakita and Walker analysis was consistent with the results obtained for Heckel analysis establishing the effect of glidants on the compaction behaviour of the granules.

CTC profiling of the granules further explained the outcome of compaction studies. The compressibility profile of the three formulations of granules was characterised by differences in the level of porosity attained in the compact across the range of pressures utilised. Compressibility has been defined as the ability of a material to undergo volume reduction when pressure is applied and is usually interpreted as a decrease in porosity of the compact formed [23,24]. Minimum porosity levels were attained with talc granules (Fig. 2A), which can be attributed to the higher degree of plasticity occurring during compaction as confirmed by Heckel analysis. Plastic deformation facilitates interparticulate contact as adjacent particles are brought together in proximity, thereby increasing the area available for bonding [25]. The compressibility of talc granules translates to greater bonding surface area when compared to the other two formulations, and this is consistent with their Heckel profiles. The compactibility plot (Fig. 2B) which illustrates the effect of densification on tensile strength of compact shows however that higher tensile strength values were obtained with formulations II \& III granules at the same level of porosity compared to formulation I granules that had better 
compressibility. Compactibility is a measure of the bonding strength per unit area which is expressed as the tensile strength of the compact. An increase in the tensile strength of compacts corresponds to an increase in bonding strength per unit area. Higher tensile strength values observed with formulations II \& III granules can be ascribed to significant interparticulate bonding occurring during compaction. This agrees with the findings of other studies where the incorporation of CSD in the formulation improved the compactibility and tensile strength of the tablets significantly $[20,21,26]$. The combined effect of the two glidants gave rise to better compactibility and tensile strength of tablets compared to the individual performance of each glidant. Hence, these two glidants used synergistically promotes bonding strength per unit area by interparticulate bond formation. Tabletability measures the capacity of powdered material to be transformed into tablets of specified strength under the effect of compression pressure $[23,27]$. The tabletability of a material is a function of its mechanical properties and is governed by the compressibility and compactibility of the material [28]. Tabletability profiles of formulations II \& III granules, as seen in Fig. 2C demonstrated better performance compared to formulation I granules owing to their better compactibility profiles. This implies therefore that compactibility and not compressibility is the major contributor to the tabletability of formulations II \& III granules. Furthermore, the tabletability profile of formulations II \& III granules may have been influenced by minimal elastic recovery occurring after compression thereby retaining to a large extent the interparticulate bonds formed during compression resulting in tablets of higher tensile strength.

The drug release profile of the three formulations as seen in Fig. 4 reflects the superdisintegrating ability of CSD which gave a faster rate and extent of drug release when compared to the other two formulations. This has been attributed to the ability of CSD to create a porous network on the surface of the tablet leading to a rapid uptake of water that facilitates the fragmentation of the tablet matrix and the release of the drug. This is consistent with the findings of Rojas et al. [26] and El-Barghouthi et al. [39] who developed co-processed excipients containing CSD that gave rise to rapid disintegration and release of tablet.

\section{CONCLUSION}

The study highlights the contribution of glidants to the compaction and tableting properties of paracetamol granules. The properties of granules formulated using different glidants did not differ significantly across the various formulations. The compaction properties differed across the various formulations of granules depending on the type of glidant used in the formulation. Talc granules had the highest degree of plasticity, implying better compressibility and bonding surface area. However, CSD granules and granules combining the action of talc and CSD as a glidant in equal proportion resulted in granules with better compactibility and tabletability, implying better bonding strength per unit area and minimum elastic recovery. There was a correlation between the compaction properties of the granules and the properties of the tablets obtained from the granules as CSD granules and granules combining the two glidants (CSD \& Talc) gave better tablets as a result of better compactibility and tabletability. This study underscores the importance of making the right choice of glidant in tablet formulation.

\section{MATERIALS AND METHODS}

\subsection{Materials}

Paracetamol, Magnesium stearate, Talc and Xylene (BDH chemicals Ltd Poole England), Maize Starch (Burgoyne Burbidge \& Co. (India), Mumbai), Colloidal silicon dioxide (Evonik Industries, Germany). All other materials and solvents used were of analytical grade.

\subsection{Preparation of paracetamol granules}

Three formulations of paracetamol granules were prepared by the wet granulation method according to the formula given in Table 4.

Paracetamol powder $(60 \mathrm{~g})$ was mixed with $3.9 \mathrm{~g}$ each of maize starch and lactose in a mortar with the aid of a pestle. The powders were mixed using the doubling up technique in order to achieve a homogeneous distribution of the powders in the final blend. The powder mix was then massed with a binder prepared by heating a dispersion of maize starch $(2.4 \mathrm{~g})$ in $10 \mathrm{~mL}$ of distilled water to form a paste. Massing was carried out for 5 mins to allow for adequate wetting of the powder mix with the binder. The wet mass obtained was force-screened through a sieve $(1.6 \mathrm{~mm})$ to generate wet granules. Drying of the granules was carried out in the oven at $40{ }^{\circ} \mathrm{C}$ for 10 mins after which it was further screened through a smaller sieve $(1.0 \mathrm{~mm})$ and then 
replaced in the oven to dry completely for a period of $2 \mathrm{~h}$. Tests were carried out on the dried granules to evaluate its physical properties.

Table 4. Formula for preparing granules and tablet per formulation

\begin{tabular}{llll}
\hline & \multicolumn{3}{l}{ Formulations of Tablets } \\
\cline { 2 - 4 } Ingredients & I & II & III \\
\hline Paracetamol (77 \%) & 60 & 60 & 60 \\
Lactose $(5 \%)$ & 3.9 & 3.9 & 3.9 \\
Maize starch (5 \%) & 3.9 & 3.9 & 3.9 \\
Maize starch paste (3 \%) & 2.34 & 2.34 & 2.34 \\
Extragranular excipients & & & \\
Maize starch (5 \%) & 3.9 & 3.9 & 3.9 \\
Talc $(2.45,4.9 \%)$ & 3.82 & - & 1.91 \\
*CSD (2.45, 4.9 \%) & - & 3.82 & 1.91 \\
Mag. Stearate (0.1 \%) & 0.078 & 0.078 & 0.078 \\
\hline Total (g) & $\mathbf{7 8}$ & $\mathbf{7 8}$ & $\mathbf{7 8}$ \\
\hline
\end{tabular}

${ }^{*} \mathrm{CSD}$ - Colloidal silicon dioxide.

\subsection{Particle size analysis}

The mean granule size (MGS) for each formulation of granules was determined using the sieving method [29]. Test sieves ranging from $1000 \mu \mathrm{m}$ to $<75 \mu \mathrm{m}$ (Pan) were arranged in descending order. Approximately $20 \mathrm{~g}$ sample of the granules was placed in the topmost sieve and allowed to vibrate for $10 \mathrm{mins}$ in the Endecott test sieve shaker to allow for separation of granules based on their different sizes. The fraction of granules retained on each sieve was weighed, and the mean granule size calculated using the formula given below.

$$
\text { Mean granule size }=[\Sigma(\% \text { retained }) \times(\text { sieve size })] / 100
$$

\subsection{Moisture content}

Moisture content retained by each formulation of granules after drying was determined gravimetrically by drying $1 \mathrm{~g}$ sample of granules in the oven at $105^{\circ} \mathrm{C}$ until a constant weight was obtained. Moisture content expressed in percentage was calculated using the equation given below

$$
\text { Moisture content }(\%)=(\text { Initial weight }- \text { Final weight }) /(\text { Initial weight }) \times 100
$$

\subsection{True density $\left(\rho_{T}\right)$}

The true density for each formulation of granules was calculated using the method reported by Alebiowu [30]. The empty weight of a pycnometer (density) bottle was obtained, filled with xylene and its weight determined. A sample of the granules weighing $2 \mathrm{~g}$ was transferred into the bottle and the excess liquid wiped off. The new weight was determined, and the equation below was used to calculate true density having obtained the weight of xylene displaced by the sample.

$$
\rho_{T}=\frac{\text { weight of sample } \times \rho \text { of } x y l e n e ~(0.864)}{\text { weight of xylene displaced by sample }}
$$

\subsection{Angle of repose}

The angle of repose for each formulation of granules was measured using the fixed funnel method [31]. About $20 \mathrm{~g}$ of granules was poured at an angle of $45^{\circ}$ through a funnel fixed at the height of $8 \mathrm{~cm}$ onto a flat surface forming a conical heap of powder. The dimensions of height and radius were measured, and the angle $(\theta)$ formed by the slanted surface with the horizontal was computed using the equation given below. A mean of three replicates was reported with the standard deviation. 
Where $h$ and $r$ are height and radius respectively.

\subsection{Bulk and tapped densities}

The bulk (BD) and tapped densities were measured in triplicate for each formulation of granules. The volume occupied by $20 \mathrm{~g}$ of granules poured into a $50 \mathrm{~mL}$ measuring cylinder was recorded as the bulk volume $\left(\mathrm{V}_{\mathrm{B}}\right)$, and the volume obtained after tapping to constant volume was recorded as the tapped volume $\left(\mathrm{V}_{\mathrm{T}}\right)$. Bulk and tapped densities were calculated using the formula given below.

$$
\begin{aligned}
& B D=\text { Weight } /\left(\text { Bulk volume }\left(V_{B}\right)\right. \\
& T D=\text { Weight } /\left(\text { Tapped volume }\left(V_{T}\right)\right.
\end{aligned}
$$

The parameters of Carr's Index (CI) and Hausner's ratio (HR) were equally calculated using the bulk and tapped densities, as shown in Equations 6 \& 7, respectively.

$$
\begin{aligned}
& C I=(T D-B D) / T D \times 100 \\
& H R=T D / B D
\end{aligned}
$$

\subsection{Compaction studies}

Tablets weighing $500 \mathrm{mg}$ were compressed for each formulation of granules at pressures ranging from $40-200 \mathrm{MPa}$ on a Hydraulic Carver Press (Carver, USA). A minimum of three (3) tablets were prepared at each compression pressure. The compacts were kept for $24 \mathrm{~h}$ before further studies to allow for elastic recovery and prevent false low yield values. Tableting parameters of weight, thickness and crushing strength were measured for all the tablets and the corresponding apparent densities $\left(\rho_{\mathrm{A}}\right)$, relative densities $(D)$ and porosities $(\varepsilon)$ of tablets were computed using the equations given below.

$$
\rho_{A}=w / v
$$

Where ' $w$ ' and ' $v$ ' is the weight and volume of the tablet, respectively.

$$
\begin{aligned}
& D=\rho_{A} / \rho_{T} \\
& \varepsilon=1-\rho_{A} / \rho_{T}
\end{aligned}
$$

The compaction equations of Heckel [32], Kawakita [33] and Walker [34,35] given below in equations $12-14$ respectively were used to generate the compaction plots utilising the data obtained from compaction studies. Compaction behaviour of granules was also assessed using the compressibility, tabletability, and compactibility (CTC) profile.

$$
\operatorname{In}\left(\frac{1}{\varepsilon}\right)=P K+A
$$

Where $E$ is the porosity of the compact, $P$ is the applied pressure, $K$ is the slope of the linear portion of the plot and $A$ is the intercept on the y axis.

$$
\frac{P}{C}=\frac{P}{a}+\frac{1}{a b}
$$


Where $C$ and $P$ represents the degree of volume reduction and compression pressure, respectively. The constant ' $a$ ' is the initial porosity of the material at the beginning of compression while the constant ' $b$ ' relates to the degree of plasticity of the material.

$$
V^{\prime}=-w^{\prime} \log P+V_{s p^{\prime}}
$$

Where $V^{\prime}$ is the specific volume of a compact and $w^{\prime}$ is the Walker coefficient expressing the volume reduction corresponding to one decade change in pressure $P$ and $V s p^{\prime}$ is the specific volume at pressure 1 .

\subsection{Tableting}

The granules to be compressed into tablets were mixed with specified quantities of extragranular excipients, as indicated in Table 4. The mixing was done for 5 mins to ensure optimal lubrication of the granules. The lubricated granules were then compressed into tablets weighing about $650 \mathrm{mg}$ on a Single Punch Tablet Press using $12 \mathrm{~mm}$ flat-faced punch and die tooling. After compression, the tablets were kept for $24 \mathrm{~h}$ before evaluation to allow for elastic recovery.

\subsection{Tablet evaluation}

The following tableting parameters were evaluated under the following tests:

\subsubsection{Uniformity in weight}

The individual weights of twenty (20) randomly selected tablets from each formulation were obtained using an electronic balance. The mean and standard deviation were computed and recorded.

\subsubsection{Tablet thickness}

The thickness of five (5) tablets randomly selected from each formulation was measured using a digital vernier calliper. A mean of five determinations was recorded with standard deviation.

\subsubsection{Crushing strength and tensile strength}

The force required to a crush a tablet diametrically was measured using a Monsanto hardness tester. A mean of five replicates was recorded as the crushing strength for each formulation of tablets. Tensile strength was calculated using the Fell and Newton [36] equation given below:

$$
T s=2 F / \pi d t
$$

Where $F, d$, and $t$ are the crushing strength, diameter, and thickness, respectively.

\subsubsection{Friability test}

Tablet friability was determined for each formulation of tablets using an Erweka Friabilator (TA 20, $\mathrm{GmbH}$, Heusenstamm, Germany). The initial weight $\left(W_{i}\right)$ of ten (10) tablets was taken, placed in the friabilator and allowed to operate at $25 \mathrm{rpm}$ for $4 \mathrm{~min}$. The final weight $\left(W_{f}\right)$ of tablets was taken after removal of dust and friability calculated as follows:

$$
\text { Friability }=\left(W_{i}-W_{f}\right) / W_{i} \times 100
$$

\subsubsection{Disintegration time}

The time taken for six (6) tablets to disintegrate from each formulation was assessed using the Disintegration tester (ZT-4, Erweka, Heusenstamm, Germany) as described by Adeoye and Alebiowu [37]. A mean of six determinations was recorded for each batch of tablets.

\subsubsection{Calibration curve of paracetamol}

Serial dilutions of paracetamol solution in phosphate buffer ( $\mathrm{pH} 5.8$ ) corresponding to $0.1-0.7 \mu \mathrm{g} / \mathrm{mL}$ were prepared from a stock solution of paracetamol in phosphate buffer $(0.1 \mathrm{mg} / \mathrm{mL})$. The absorbances of the serial dilutions were obtained spectrophotometrically at a wavelength of $244 \mathrm{~nm}$ and a graph of absorbance 
against concentration was plotted. The equation of the straight line derived from the plot was used to compute the amount of drug released during dissolution studies.

\subsubsection{In vitro drug release studies}

In vitro drug release studies were carried out according to the method adopted by Adjei et al. [38] for paracetamol tablets. The experiment was conducted using an Erweka dissolution apparatus (Type DT6, $\mathrm{GmbH}$, Heusenstamm, Germany) under sink conditions. The rotating basket mode, operating at $50 \mathrm{rpm}$, was employed in a dissolution medium of phosphate buffer (pH 5.8) set to $37 \pm 0.5^{\circ} \mathrm{C}$. Samples were withdrawn at time intervals of 5, 10, 20, 30, 45, 60 mins and replaced with an equal volume of the dissolution medium after each withdrawal. The withdrawn samples were suitably diluted with the buffer, and the absorbance values read at $244 \mathrm{~nm}$ using the UV spectrophotometer (Shimadzu, Corporation, USA). The amount of paracetamol released was calculated using the equation from the calibration curve and a plot of the quantity of drug released (\%) against time was drawn for the three formulations of tablets.

Acknowledgements: We acknowledge the contribution of the technologists during the studies.

Author contributions: Concept - Y.E.A; Design - Y.E.A., A.K.O.; Supervision - A.K.O.; Materials - Y.E.A.; Data Collection and/or Processing - Y.E.A..; Analysis and/or Interpretation - Y.E.A., A.K.O.; Literature Search - Y.E.A.; A.K.O.; Writing - Y.E.A.; Critical Reviews - Y.E.A., A.K.O.

Conflict of interest statement: "The authors declare no conflict of interest" in the manuscript.

\section{REFERENCES}

[1] Chang R, Leonzio M, Hussain M, Hussain M. Effect of colloidal silicon dioxide on flowing and tableting properties of an experimental, crosslinked polyalkylammonium polymer. Pharm Dev Technol. 1999; 4: 285-289. [CrossRef]

[2] Jonat S, Hasenzahl S, Gray A, Schmidt P. Influence of compacted hydrophobic and hydrophilic colloidal silicon dioxide on tableting properties of pharmaceutical excipients. Drug Dev Ind Pharm. 2005; 31: 687-696. [CrossRef]

[3] Wang J, Wen H, Desai D. Lubrication in tablet formulations. Eur J Pharm Biopharm. 2010; 75: 1-15. [CrossRef]

[4] Perrault M, Bertrand F, Chaouki J. An experimental investigation of the effect of the amount of lubricant on tablet properties. Drug Dev Ind Pharm. 2011; 37: 234-242. [CrossRef]

[5] Morin G, Briens L. The effect of lubricants on powder flowability for pharmaceutical application. AAPS PharmSciTech. 2013; 14: 1158-1168. [CrossRef]

[6] Zaman M. B. Pharm Thesis. Determination of variation in flow property of different formulas of lactose along with amlodipine and propranolol. Department of Pharmacy, East West University, Bangladesh, 2016.

[7] Osei-Yeboah F, Sun CC. Tabletability modulation through surface engineering. J Pharm Sci. 2015; 104: 2645-2648. [CrossRef]

[8] Müller A, Ruppel J, Drexel C, Zimmermann I. Precipitated silica as flow regulator. Eur J Pharm Sci. 2008; 34: 303308. [CrossRef]

[9] Nurnberg E. Experimentelle Prüfungen von direct verpreßten Tablettengrundlagen. Pharm Ind. 1972; 34: $193-206$.

[10] Rashid I, Al-Remawi M, Eftaiha A, Badwan A. Chitin-silicon dioxide coprecipitate as a novel superdisintegrant. J Pharm Sci. 2008; 97: 4955-4969. [CrossRef]

[11] Pingali K, Mendez R, Lewis D, Michniak-Kohn B, Cuitino A, Muzzio F. Mixing order of glidant and lubricantInfluence on powder and tablet properties. Int J Pharm. 2011; 409: 269-277. [CrossRef]

[12] Majerova D, Kulaviak L, Ruzicka M, Stepanek F, Zámostny P. Effect of colloidal silica on rheological properties of common pharmaceutical excipients. Eur J Pharm Biopharm. 2016; 106: 2-8. [CrossRef]

[13] Tran DT, Majerová D, Veselý M, Kulaviak L, Ruzicka MC, Zámostný P. On the mechanism of colloidal silica action to improve flow properties of pharmaceutical excipients. Int J Pharm. 2019; 556: 383-394. [CrossRef]

[14] Arora V, Gupta VB, Singhal R. Advances in direct compression technology. Pharma Times. 2007; 39: 26-27.

[15] Jadhav NR, Paradkar AR, Salunkhe NH, Karade RS, Mane GG. Talc : a versatile pharmaceutical excipient. World J Pharm Pharm Sci. 2013; 2: 4639-4660.

[16] Ariko NA. B. Pharm Thesis. Optimization of the extragranular component in paracetamol tablet formulation using Quality by Design. Department of Pharmaceutics and Industrial Pharmacy, Faculty of Pharmaceutical Sciences, Ahmadu Bello University, Zaria, Nigeria, 2015. 
[17] Patel S, Kaushal AM, Bansal AK. The effect of starch paste and sodium starch glycolate on the compaction behavior of wet granulated acetaminophen formulations. J Excipients Food Chem. 2011; 2(3): 64-72.

[18] Osei-Yeboah F, Feng Y, Sun CC. Evolution of structure and properties of granules containing microcrystalline cellulose and polyvinylpyrrolidone during high-shear wet granulation. J Pharm Sci. 2014; 103: 207-215. [CrossRef]

[19] Patel S, Kaushal AM, Bansal AK. Compression physics in the formulation development of tablets. Crit Rev Ther Drug Carrier Syst. 2006; 23: 1-65. [CrossRef]

[20] Rahmouni M, Lenaerts V, Massuelle D, Doelker E, Leroux J. Influence of physical parameters and lubricants on the compaction properties of granulated and non-granulated cross-linked high amylose starch. Chem Pharm Bull. 2002; 50: 1155-1162. [CrossRef]

[21] Sadeghi F, Mosaffa F, Garekani HA. Effect of particle size , compaction force and presence of aerosil 200 on the properties of matrices prepared from physical mixture of propranolol hydrochloride and Eudragit RS or RL. Iran J Basic Med Sci. 2007; 10: 197-205.

[22] Sun CC. Decoding powder tabletability: roles of particle adhesion and plasticity. J Adhes Sci Technol. 2011; 25: 483499. [CrossRef]

[23] Joiris E, Di Martino P, Berneron C, Guyot-Hermann A, Guyot J. Compression behavior of orthorhombic paracetamol. Pharm Res. 1998; 15: 1122-1130. [CrossRef]

[24] Upadhyay P, Khomane KS, Kumar L, Bansal AK. Relationship between crystal structure and mechanical properties of ranitidine hydrochloride polymorphs. CrystEngComm. 2013; 15: 3959-3964. [CrossRef]

[25] Osei-Yeboah F, Chang S, Sun CC. A critical examination of the phenomenon of bonding area - bonding strength interplay in powder tableting. Pharm Res. 2016; 33: 1126-1132. [CrossRef]

[26] Rojas J, Kumar V. Comparative evaluation of silicified microcrystalline cellulose II as a direct compression vehicle. Int J Pharm. 2011; 416: 120-128. [CrossRef]

[27] Krishna GR, Shi L, Bag PP, Sun CC, Reddy CM. Correlation among crystal structure, mechanical behavior, and tabletability in the co-crystals of vanillin isomers. Cryst Growth Des. 2015; 15: 1827-1832. [CrossRef]

[28] Yadav JA, Khomane KS, Modi SR, Ugale B, Yadav RN, Nagaraja CM, Kumar N, Bansal AK. Correlating single crystal structure, nanomechanical, and bulk compaction behavior of febuxostat polymorphs. Mol Pharm. 2017; 14: 866-874. [CrossRef]

[29] Allen L, Popovich N, Ansel H. Powders and granules. In: Allen L, Popovich N, Ansel H. (Eds). Ansel's Pharmaceutical Dosage Forms and Drug Delivery Systems. Lippincott Williams \& Wilkins, New York, 2005, pp. 186203.

[30] Alebiowu G. Studies on the tableting properties of Sorghum Bicolor Linn (Poaceae) starch I: Evaluation of binder types and concentrations on the properties of sorghum starch granulations. Discov Innov. 2001; 13: 73-77. [CrossRef]

[31] Szumilo M, Belniak P, Swiader K, Holody E, Poleszak E. Assessment of physical properties of granules with paracetamol and caffeine. Saudi Pharm J. 2017; 25: 900-905. [CrossRef]

[32] Heckel RW. Density-pressure relationships in powder compaction. Trans Metall Soc AIME. 1961; 221: 671-675.

[33] Kawakita K, Lüdde KH. Some considerations on powder compression equations. Powder Technol. 1971; 4: 61-68. [CrossRef]

[34] Walker EE. The properties of powders. Part VI. The compressibility of powders. Trans Faraday Soc. 1923; 19: 73-82. [CrossRef]

[35] Sonnergaard JM. A critical evaluation of the Heckel equation. Int J Pharm. 1999; 193: 63-71. [CrossRef]

[36] Fell J, Newton J. Determination of tablet strength by the diametral-compression test. J Pharm Sci. 1970; 59: 688-691. [CrossRef]

[37] Adeoye O, Alebiowu G. Evaluation of co-processed disintegrants produced from tapioca starch and mannitol in orally disintegrating paracetamol tablets. Acta Pol Pharm ñ Drug Res. 2014; 71(5): 803-811.

[38] Adjei FK, Osei YA, Kuntworbe N, Ofori-kwakye K. Evaluation of the disintegrant properties of native starches of five new cassava varieties in paracetamol tablet formulations. J Pharm 2017; 2017: 1-9. [CrossRef]

[39] El-Barghouthi M, Eftaiha A, Rashid I, Al-Remawi M, Badwan A. A novel superdisintegrating agent made from physically modified chitosan with silicon dioxide. Drug Dev Ind Pharm. 2008; 34: 373-383. [CrossRef]

This is an open access article which is publicly available on our journal's website under Institutional Repository at http://dspace.marmara.edu.tr. 